Final Report

for

CRADA Number NFE-08-01498

\section{Materials for High-Pressure Fuel Injection Systems}

Peter Blau, Amit Shyam, Camden Hubbard, Jane Howe, and Rosa Trejo Oak Ridge National Laboratory

and

Nan Yang and Michael Pollard Caterpillar Inc. Technical Center Mossville, Illinois

Prepared by

Oak Ridge National Laboratory

Oak Ridge, TN 37831

Managed by

UT-BATTELE, LLC

for the

U.S. Department of Energy

Under contract DE-AC05-00PR2225

September 30, 2011

Approved for

Unlimited Distribution

UT-BATTELLE 


\section{DOCUMENT AVAILABILITY}

Reports produced after January 1, 1996, are generally available free via the U.S. Department of Energy (DOE) Information Bridge.

Web site http://www.osti.gov/bridge

Reports produced before January 1, 1996, may be purchased by members of the public from the following source.

National Technical Information Service

5285 Port Royal Road

Springfield, VA 22161

Telephone 703-605-6000 (1-800-553-6847)

TDD 703-487-4639

Fax 703-605-6900

E-mail info@ ntis.gov

Web site http://www.ntis.gov/support/ordernowabout.htm

Reports are available to DOE employees, DOE contractors, Energy Technology Data Exchange (ETDE) representatives, and International Nuclear Information System (INIS) representatives from the following source.

Office of Scientific and Technical Information

P.O. Box 62

Oak Ridge, TN 37831

Telephone 865-576-8401

Fax 865-576-5728

E-mail reports@osti.gov

Web site http://www.osti.gov/contact.html

This report was prepared as an account of work sponsored by an agency of the United States Government. Neither the United States Government nor any agency thereof, nor any of their employees, makes any warranty, express or implied, or assumes any legal liability or responsibility for the accuracy, completeness, or usefulness of any information, apparatus, product, or process disclosed, or represents that its use would not infringe privately owned rights. Reference herein to any specific commercial product, process, or service by trade name, trademark, manufacturer, or otherwise, does not necessarily constitute or imply its endorsement, recommendation, or favoring by the United States Government or any agency thereof. The views and opinions of authors expressed herein do not necessarily state or reflect those of the United States Government or any agency thereof. 


\title{
Materials for High-Pressure Fuel Injection Systems
}

DOE Agreement number

“DE-FG36-06GO16054”

\author{
CRADA Final Report \\ (CRADA Number NFE-08-01498)
}

\author{
Peter Blau, Amit Shyam, Camden Hubbard, \\ Jane Howe, and Rosa Trejo \\ Oak Ridge National Laboratory \\ in Partnership with \\ Nan Yang and Michael Pollard \\ Caterpillar Inc. Technical Center \\ Mossville, Illinois
}




\section{Foreword}

This Cooperative Research and Development Agreement (CRADA number NFE-08-01498;

DOE Agreement Number DE-FG36-06GO16054) was effective from 14 July 2008 through 30 September 2011. Funding was provided by the U.S. Department of Energy, Office of Energy Efficiency and Renewable Energy, Office of Vehicle Technologies. Participants for the ORNL portion of this CRADA included Peter J. Blau (Principal Investigator), Amit Shyam, Camden R. Hubbard, Rosa Trejo, Randy Parten, Brian Jolly, Tom Geer, Jane Howe, and Dorothy Coffey, all of the Materials Science and Technology Division. Participation from Caterpillar, Inc. varied over the course of the project, beginning with Jeff Jensen, Michael Pollard (initial Principal Investigator), and Ally Stahl. In year 3, Nan Yang took over as Caterpillar’s Principal Investigator.

No proprietary or other commercially-sensitive information has been included in this final report. Therefore, no descriptions of specific alloy compositions, processing steps, or heat treatments that are now used, or are being contemplated for use in commercial diesel engine fuel systems, have been included. The information contained herein is intended to document the research methods and principal findings conducted by the partners in this collaborative effort. Several papers have been prepared in conjunction with this work, and the reader is also referred to those references, listed in Section 5.2. 


\section{CONTENTS}

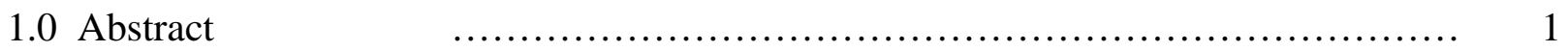

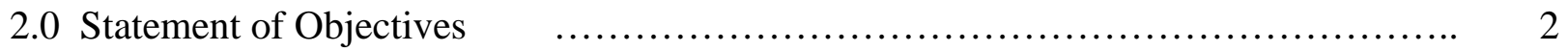

3.0 Benefits to the Funding DOE Office’s Mission $\quad \ldots \ldots \ldots \ldots \ldots \ldots \ldots \ldots \ldots \ldots \ldots \ldots . \ldots \ldots$

4.0 Technical Discussion of Work Performed by All Parties $\quad$................ 3

4.1 General Description of Nozzles $\quad$............................ 3

4.2 Microstructures and Hardness Characterization $\quad$............................ 4

4.2.1 Microstructure of Nozzles $\quad$................................... 4

4.2.2 Micro- and Nano-indentation of Nozzle Cross-Sections $\quad$............ 8

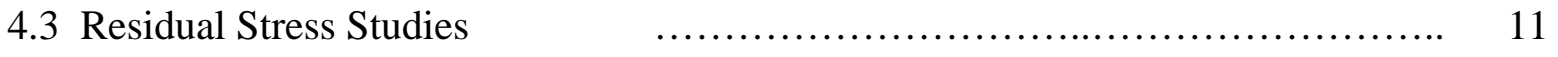

4.4 Fatigue Studies

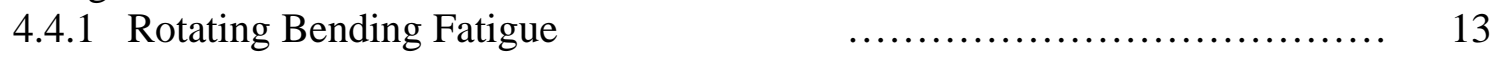

4.4.2 Smooth Axial Fatigue $\quad$................................. 15

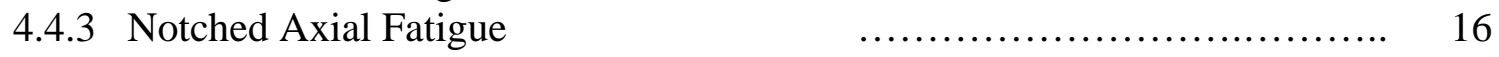

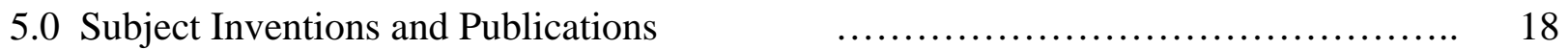

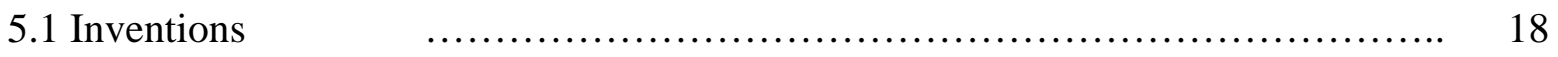

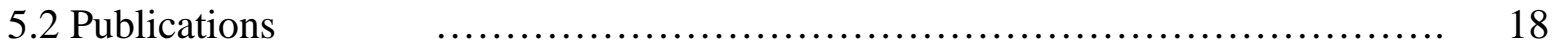

6.0 Commercialization Possibilities $\quad$.................................. 18

7.0 Plans for Future Collaboration $\quad$.................................... 19

8.0 Conclusions $\quad$............................................. 19

9.0 References $\quad$.............................................. 20

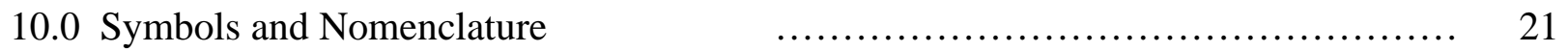




\subsection{Abstract}

The high-level goal of this multi-year effort was to facilitate the Advanced Combustion Engine goal of 20\% improvement (compared to 2009 baseline) of commercial engine efficiency by 2015. A sub-goal is to increase the reliability of diesel fuel injectors by investigating modelbased scenarios that cannot be achieved by empirical, trial and error methodologies alone. During this three-year project, ORNL developed the methodology to evaluate origins and to record the initiation and propagation of fatigue cracks emanating from holes that were electrodischarge machined (EDM), the method used to form spray holes in fuel injector tips.

Both x-ray and neutron-based methods for measuring residual stress at four different research facilities were evaluated to determine which, if any, was most applicable to the fuel injector tip geometry. Owing to the shape and small volumes of material involved in the sack area, residual stress data could only be obtained in the walls of the nozzle a few millimeters back from the tip, and there was a hint of only a small compressive stress. This result was consistent with prior studies by Caterpillar. Residual stress studies were suspended after the second year, reserving the possibility of pursuing this in the future, if and when methodology suitable for injector sacks becomes available.

The smooth specimen fatigue behavior of current fuel injector steel materials was evaluated and displayed a dual mode initiation behavior. At high stresses, cracks started at machining flaws in the surface; however, below a critical threshold stress of approximately $800 \mathrm{MPa}$, cracks initiated in the bulk microstructure, below the surface. This suggests that for the next generation for high-pressure fuel injector nozzles, it becomes increasingly important to control the machining and finishing processes, especially if the stress in the tip approaches or exceeds that threshold level.

Fatigue tests were also conducted using EDM notches in the gage sections. Compared to the smooth specimens, EDM notching led to a severe reduction in total fatigue life. A reduction in fatigue life of nearly four orders of magnitude can occur at an EDM notch the approximate size of fuel injector spray holes. Consequently, the initiation and propagation behavior of cracks from small spray holes is relevant for generation of design quality data for the next generation diesel fuel injection devices. This is especially true since the current design methodologies usually rely on the less conservative smooth specimen fatigue testing results, and since different materials can have varying levels of notch fatigue resistance. 


\subsection{Statement of Objectives}

The Caterpillar/ORNL CRADA Statement of Work indicates the following purpose:

"The purpose of this Cooperative Research and Development Agreement between UT-Battelle, LLC (the "Contractor") and Caterpillar Corporation ("the Participant") is to advance the state of the art in the characterization, selection, and use of metallic alloys for use in high-pressure diesel engine fuel injector nozzles."

The overall goal of this effort is to facilitate the Advanced Combustion Engine goal of 20\% improvement (compared to 2009 baseline) of commercial engine efficiency by 2015. Sub-goals are to characterize the effects of manufacturing-induced residual stresses, to characterize asmanufactured and heat-treated alloy microstructures, and to investigate the effects of spray holes in fuel injector tips on fatigue crack initiation and propagation in current alloys. A further goal is to identify candidate, new alloys that might perform better than the current one in the highpressure fuel injection environment. The latter was a proprietary aspect of this work and is not presented in this report.

\subsection{Benefits to the Funding DOE Office's Mission}

During recent decades, fuel efficient, low-emissions diesel engine designs for heavy trucks have relied upon increasing fuel injection pressures to optimize combustion characteristics [1]. Precise fuel metering is required. This key functional requirement has raised concerns over the ability of spray holes to be machined to sufficiently close tolerances to provide desired spray patterns and for the materials to withstand millions of high-pressure pulses without succumbing to fatigue damage. Therefore, fuel injectors are an enabling technology for achieving goals of high fuel efficiency and emission controls. The benefits of this program were described in the original, multi-partner CRADA, Statement of Work. It states the following:

"The data and analyses obtained by the Parties in the course of this work are expected to provide vital information for designers of high-performance fuel systems for advanced, energy-efficient diesel engines.”

Specifically, this effort supports the DOE Vehicle Technologies 2011-2015 Multi-Year Program Plan, most recently published in December 2010 (page 2.5-7).

"By 2015, develop materials and materials processing techniques to enable the development of fuel injection systems with pressures of over 2800 Bar.” 


\subsection{Technical Discussion of Work Performed by All Parties}

To achieve the objectives of this effort, a five-pronged, three-year effort is planned. Each task addresses a part of the technical challenge and will provide new tools and data for engine designers. These tasks were originally described as follows:

1) Develop and use advanced $x$-ray and neutron diffraction methods to measure residual stresses near injector spray holes and in the bulk material deeper within the nozzle tip,

2) Develop and use specialized hole examination methods to characterize not only the dimensions, but also the interior bore roughness of spray holes produced by current production methods,

3) Develop a means to perform pressure-induced fatigue tests on injector materials in the vicinity of holes,

4) Characterize and understand the physical metallurgy of current and candidate nozzle tip materials, relating their microstructures to residual stress and fatigue performance,

5) Provide hole characterization information to improve the accuracy of fuel injector models.

The data and analyses obtained by the Parties in the course of this work are expected to provide key information for designers of high-performance fuel systems for advanced, energy-efficient diesel engines.

\subsection{General Description of Nozzles.}

Figure 1(a) shows several diesel engine fuel injector tips, and Figure 1(b) is a close up of the spray holes in the 'sack' of an unused nozzle. Several methods were employed to characterize the holes and near-hole materials. Some of these involved imaging and dimensional measurements and others involved residual stress measurement by x-ray and neutron methods. Each aspect of the characterization is described in a separate subsection. 


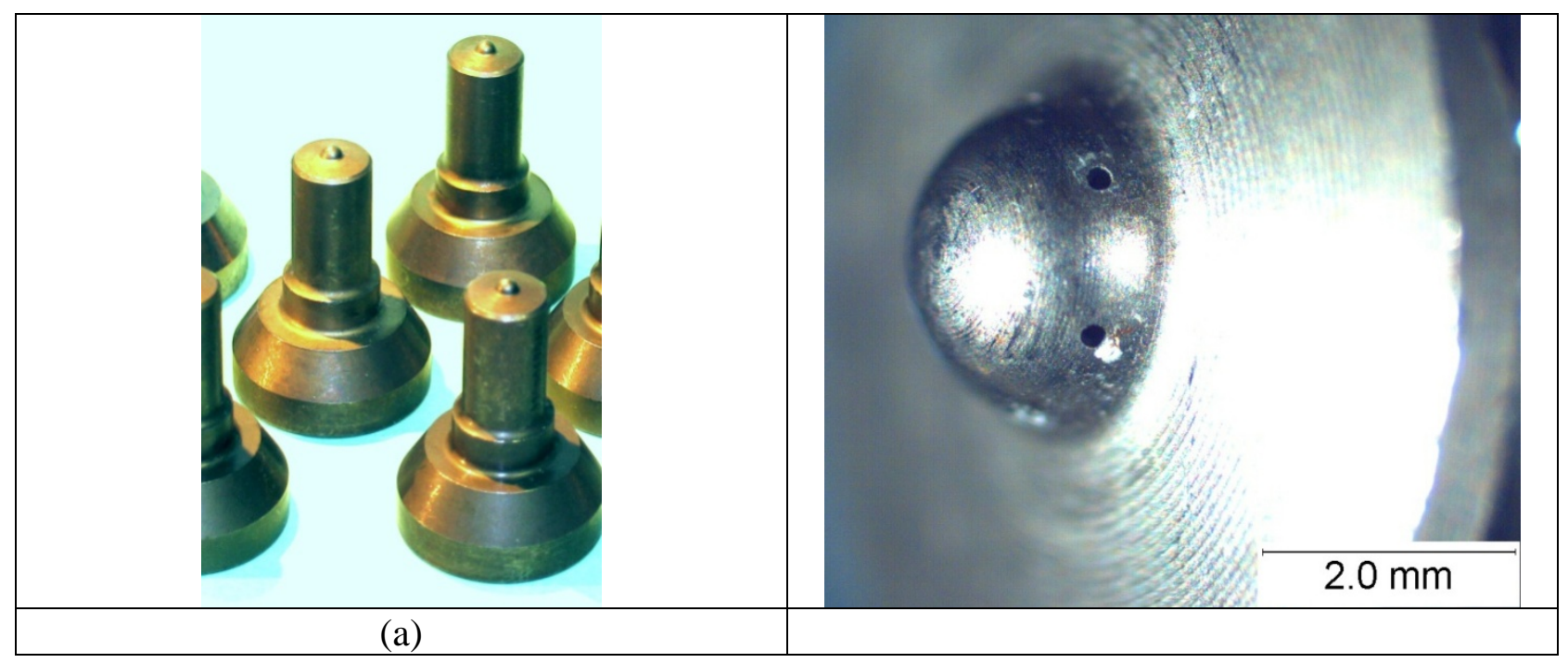

Figure 1. Fuel injectors of the type characterized here: (a) finished nozzles, (b) close-up of a sack.

\subsection{Microstructures and Hardness Characterization}

\subsubsection{Microstructure of Nozzles and Hole Walls.}

Due to the conventional electro-discharge machining process used to produce spray holes, the walls consisted of a 'recast layer' of overlapping splats (see Figures 2 a,b). If stresses during high pressure operation were localized in such areas, the micro-scale features in these hole walls could serve as stress concentrators to nucleate fatigue cracks. No evidence of crack nucleation of such fatigue cracks was observed in retrieved engine components provided by Caterpillar; however, that does not mean that the presence of such features would be benign, especially if future fuel injectors were made to operate at much higher pressures.

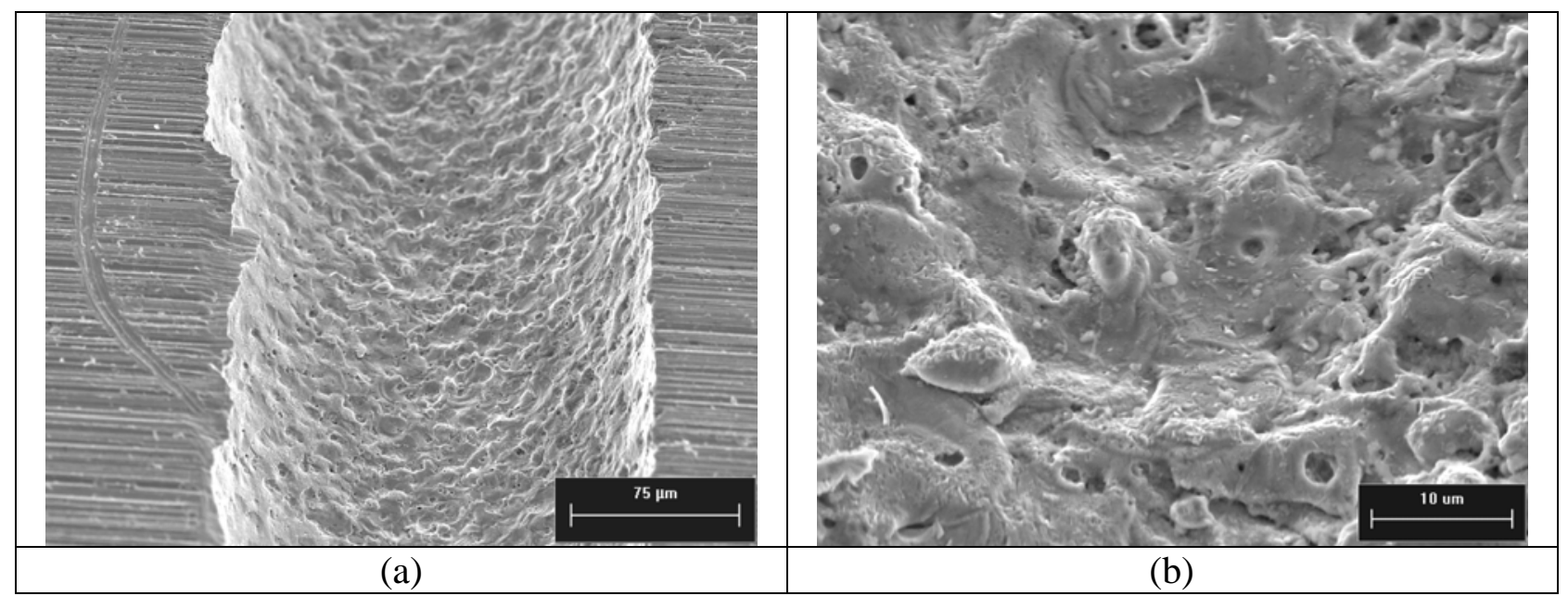

Figure 2. Structure of a spray hole wall. Figure (b) is an area of the same wall at higher magnification (scanning electron microscope (SEM) images). 
A commercial surface imaging and measurement instrument (Wyko Model NT9100, Brucker Instruments) was used to measure the hole wall roughness on the specimen in Figure 2. Two parameters were measured at three locations along the axial direction of the hole: the arithmetic average roughness $(\mathrm{Ra})$ and the ten-point height $(\mathrm{Rz})$, which is the vertical distance between the highest five peaks and lowest five valleys in a sampling length. Data are reported in Table 1.

Table 1. Roughness of a Spray Hole Wall

\begin{tabular}{|l|c|c|c|c|}
\hline Parameter & $\begin{array}{c}\text { Measurement 1 } \\
(\mu \mathrm{m})\end{array}$ & $\begin{array}{c}\text { Measurement 2 } \\
(\mu \mathrm{m})\end{array}$ & $\begin{array}{c}\text { Measurement 3 } \\
(\mu \mathrm{m})\end{array}$ & $\begin{array}{c}\text { Average } \\
(\mu \mathrm{m})\end{array}$ \\
\hline $\mathrm{Ra}$ & 0.61 & 0.53 & 0.58 & 0.57 \\
\hline $\mathrm{Rz}$ & 3.57 & 3.31 & 3.08 & 3.32 \\
\hline
\end{tabular}

Following SEM examination, cross-sections of other nozzles were polished and etched with Ralph's etch* (developed by Carpenter Technology Corporation), to enable studies of the microstructure in the sack area and to enable characterization of micro-mechanical properties. Residual stress studies, reported in 4.3, established that there was a relatively low level of residual compressive stress in the interior of these nozzles; therefore, the microstructures produced during processing and hole-making were expected to most directly influence the properties of the nozzles. Figure 3 shows a deeply-etched cross section of a sack (a) and a closeup of the area adjacent to a hole (b). Injector holes show up as ellipses due to the inclination of the plane of polish relative to the angle in which the six circular holes were produced. Due to the heat treatment given the nozzle, there was a radial variation in the coarseness of the grain structure of the sack (see Fig. 3a). This variation in microstructure corresponded to a variation in microindentation hardness across the tip, as is discussed in 4.2.2

Higher magnification scanning electron micrographs of the microstructure of the nozzle and the material adjacent to the hole wall are shown in Figures 4(a) and (b), respectively. In the bulk material, a fine carbide structure can be seen. Near the hole wall, a more etch-resistant layer, appearing white in light optical images, can be seen. Careful examination of this layer reveals very fine-scale microcracks near the free surface. Their presence suggests that the cooling process during hole drilling by EDM may have induced fine 'quench cracks.'

*Ralph's etch: $25 \mathrm{ml}$ distilled water, $50 \mathrm{ml}$ methyl alcohol, $3 \mathrm{ml}$ nitric acid, $25 \mathrm{ml}$ hydrochloric acid, $0.5 \mathrm{~g}$ copper chloride (II), $1 \mathrm{~g}$ ferric chloride (III). 


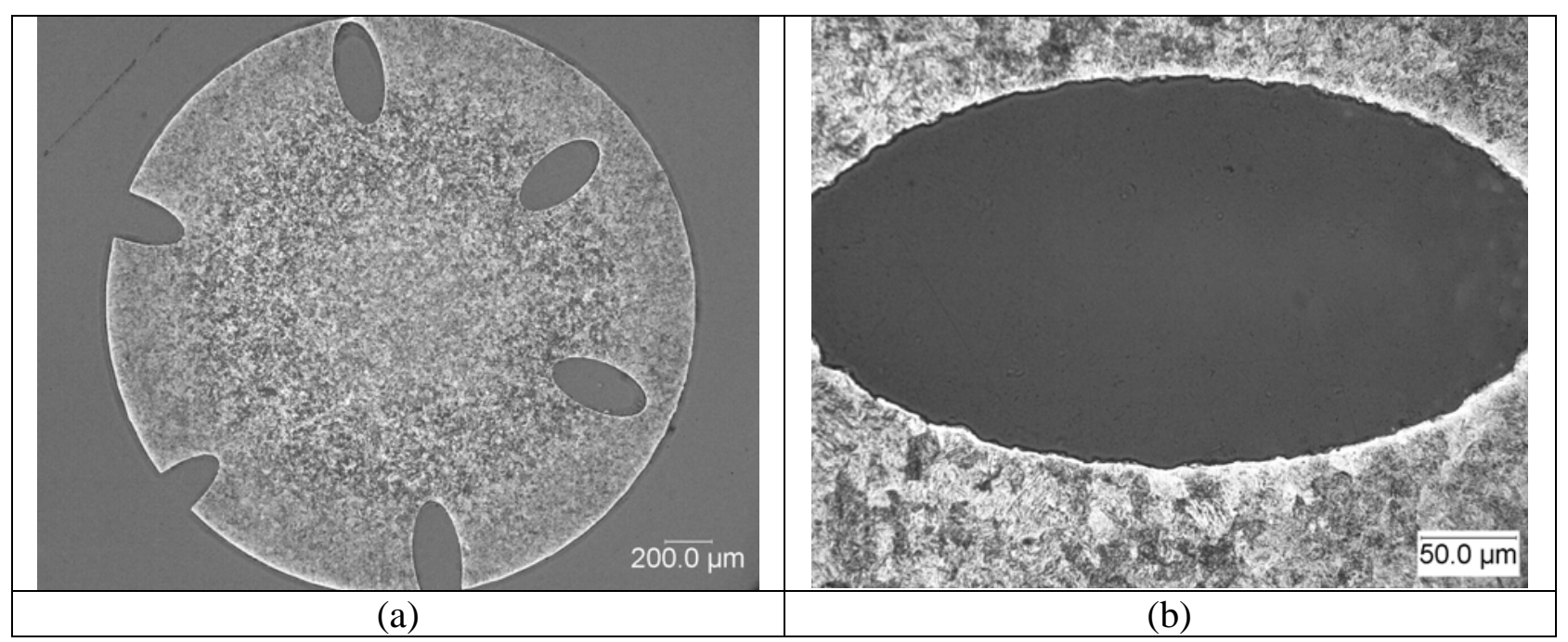

Figure 3. Etched cross-section across the top of a sack showing six spray holes (a), and details of the microstructure surrounding the hole at the upper right (b).

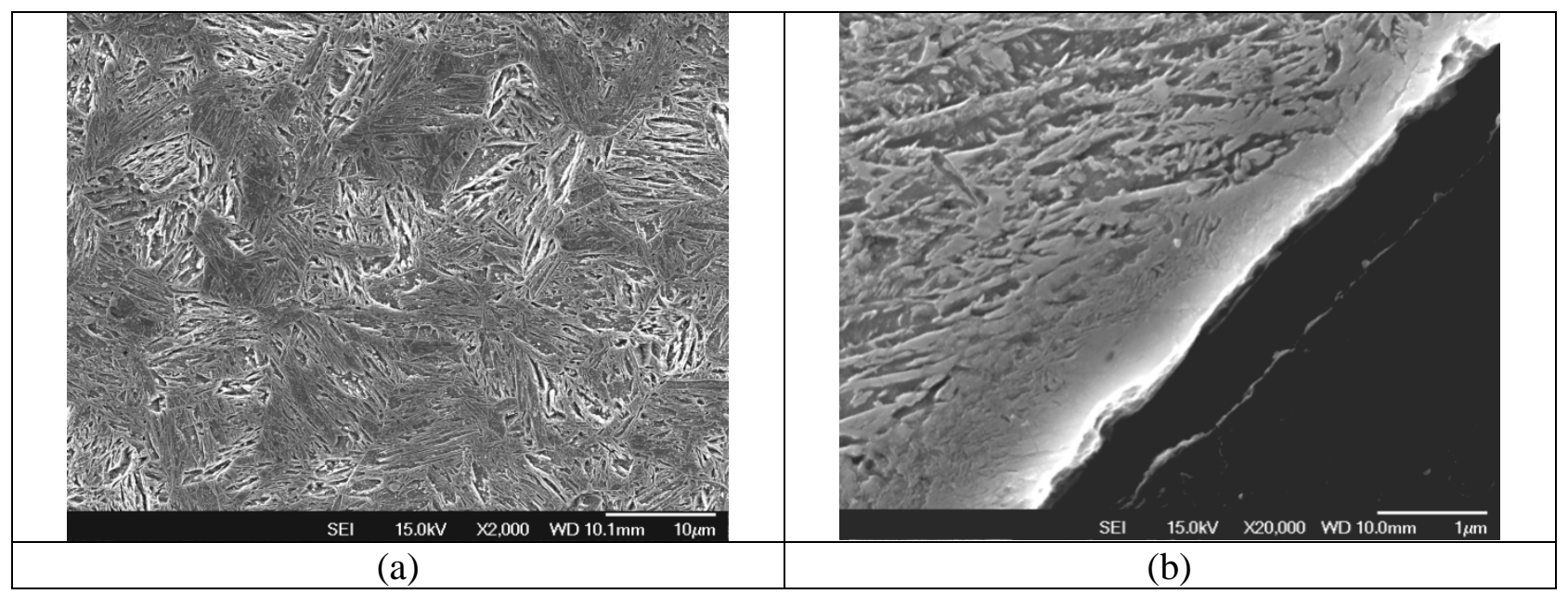

Figure 4. Ralph's etch reveals a carbide structure within the grains of the sack wall, $0.65 \mathrm{~mm}$ from the outside surface (a), and the change in microstructure near the wall of a hole.

Further detail in the very thin recast layers on spray hole walls was obtained using a precision sample preparation technique known as Focused Ion Beam (FIB) thinning. Using FIB, it was possible to extract a sliver of material from the spray hole wall for cross-sectional examination. In this case, the plane of the section was parallel to the axial direction of the hole (Fig. 5(a)). A Hitachi NB-5000 Dual FIB system was used. The "lift-out" specimen is a $7 \mu \mathrm{m} x 7 \mu \mathrm{m}$ sized slice, less than $120 \mathrm{~nm}$ thick. The FIB specimen was then imaged in a Hitachi HF-3300 TEM/STEM operating at an accelerating voltage of $300 \mathrm{kV}$. Energy-dispersive X-ray spectroscopy (EDS) was used in conjunction with imaging in order to determine the chemical composition of certain features in the recast layer. 


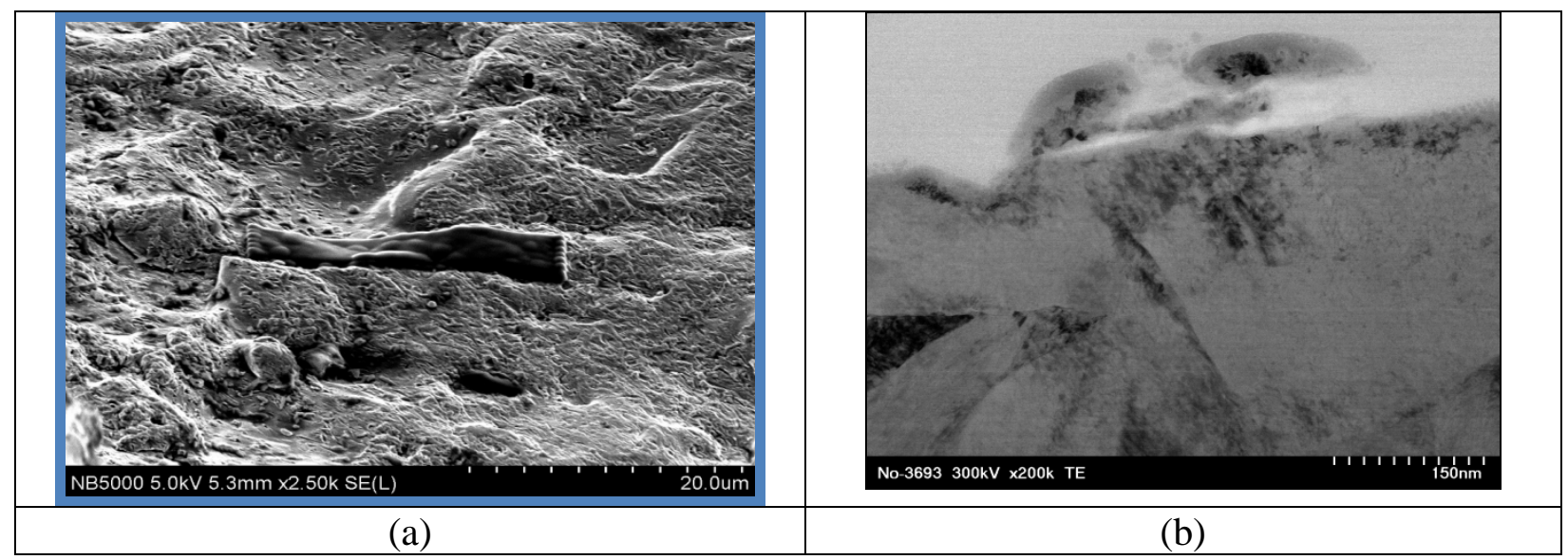

Figure 5. Preparation and structure of recast layer. (a) Area on the hole wall to be removed by the FIB, (b) Brightfield TEM image reveals a flap of recast layer that is connected by only a very small neck (left of center).

Figure 5(b) shows fragments of the recast layer on the hole wall. EDS analysis of these two separate pieces showed that their compositions were almost identical to that of the recast layer on the hole wall. EDS also detected oxygen in the area between the separated recast layer and the surface, suggesting the presence of an oxide. The bright-field TEM images reveal the crystalline (phase) information of a material. In 'Z-contrast' dark-field micrographs, image contrast increases in proportion to the atomic number $(Z)$ squared enabling one to discern features such as a precipitate or an oxide scale. The nanostructure of an up-raised portion of the recast layer is shown in Figure 6. The recast layer resembles an ocean wave, and was clearly attached to the surface. Elongated grains lay parallel to the free surface of the "wave-front" (see Fig. 6(a)). These elongated grains are $<30 \mathrm{~nm}$ wide and have an aspect ratio $>6$. However, the grains at the opposite face of the wave-front are more equiaxed. The Z-contrast micrograph in Fig. 6(b) reveals numerous spherical grains (darker dots of 7 to $20 \mathrm{~nm}$ in diameter) near the surface. EDS analysis indicated that these darker spheres are rich in vanadium and chromium. High temperature processes may have caused precipitation of such V and Cr rich grains.

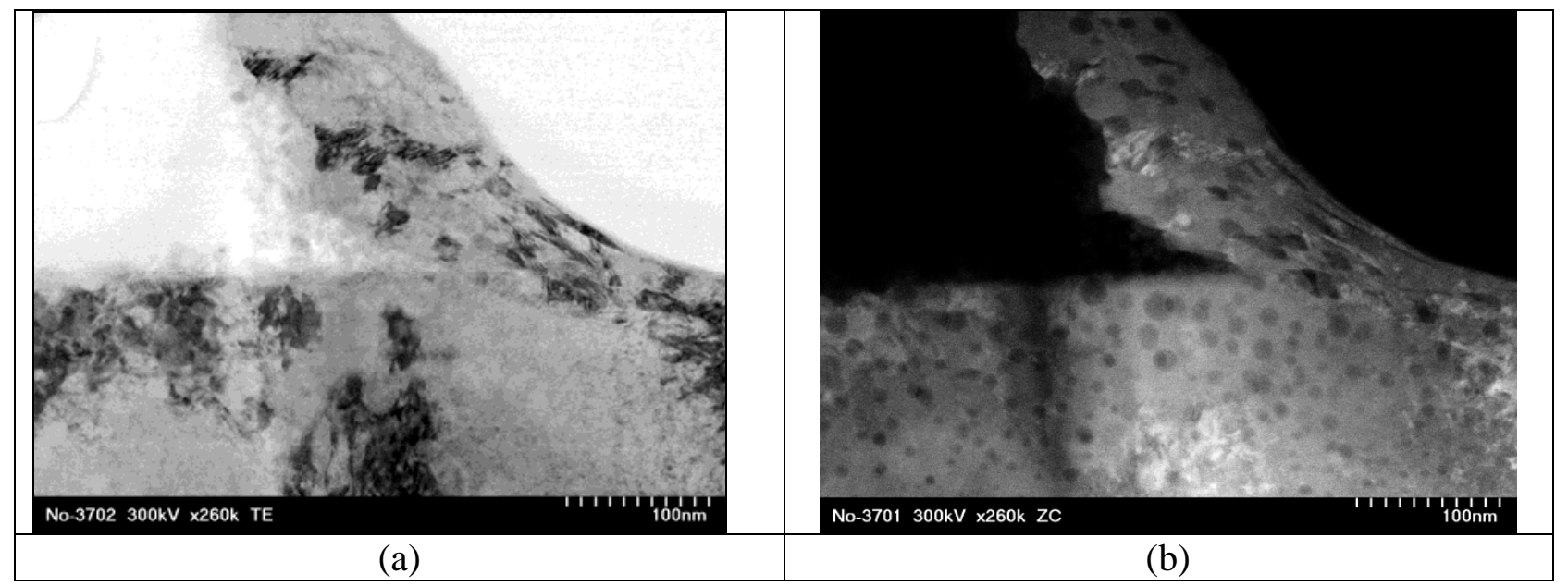

Figure 6. Nanostructure of the edge of an up-raised portion of the recast layer: (a) Bright-field TEM image reveals elongated grains parallel to the surface of the wave; (b) Z-contrast dark-field TEM image showed vanadium- and chromium-rich grains near and at the surface of the alloy 
TEM examination established that the recast layers from EDM have a varied thickness of up to $200 \mathrm{~nm}$ and a wave-like morphology. Some features could have cracks and pores underneath. The recast layers experienced high heat and directional plastic flow. The grains in the recast layer are nanocrystalline, sometimes associated with flow features. Part of the surface has a layer of oxides less than $100 \mathrm{~nm}$ thick, which contains particles that are richer in $\mathrm{Cr}$ than the matrix. The oxide scale is dense and bonds well with the matrix. Some particles inside the oxide scales are about $20 \mathrm{~nm}$ or less in diameter. The near-surface area has $50 \mathrm{~nm}$ diameter spherical grains, possibly $\mathrm{V}$ - or Cr-rich carbides.

\subsubsection{Micro- and Nano-indentation of Nozzle Cross-Sections}

Figure 7 shows the polished, unetched cross-section oriented straight across the tip of a sack, parallel to the base. The specimen was sectioned at a location far enough below the top to reveal the central cavity. Figure 8 displays a plot of the Vickers microindentation hardness, HV (103 g$\mathrm{f}$ normal force) as a function of distance from the center cavity to the outer surface. Because the section is through a roughly hemispherical tip, the radial distance from the inner cavity to the outside on the plane of polish on the photomicrograph appears larger than the actual wall thickness of the sack. However, the data reveal that the HV at the mid-thickness of the wall, where the grains are coarser (see Fig 3(a)), is approximately $25 \%$ lower than that of the finegrained zones nearer the inner and outer surfaces. This hardness gradient was a result of the nozzle heat treatment process.

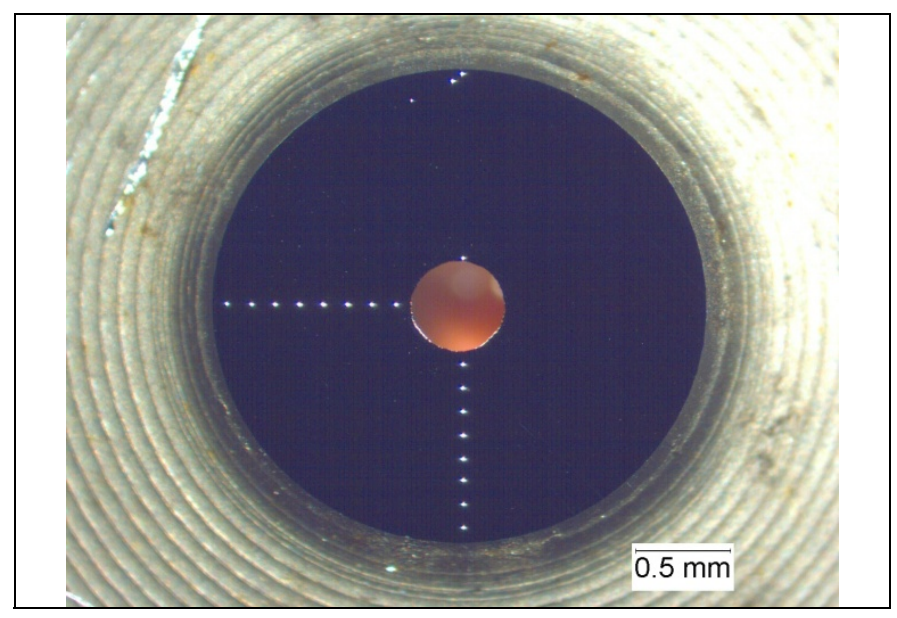

Figure 7. Polished cross-section of a tip showing two HV traces at 90 degrees to one another, reaching from the center cavity of the sack to the outside surface. Spray holes are not visible in the plane of this cross-section which is located closer to the tip than the holes. 


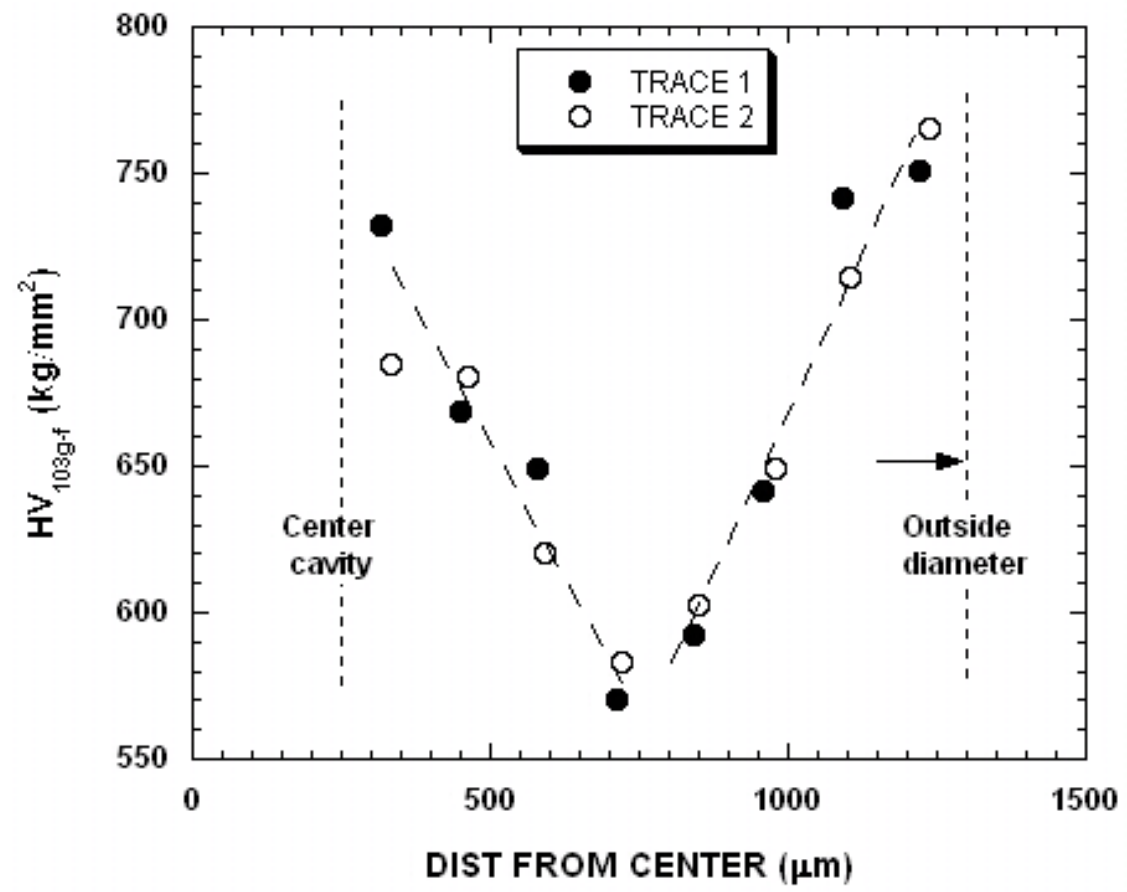

Figure 8. Variations in HV through the wall of a sack (the two sets of impressions are shown in Figure 7).

The variation of mechanical properties through the wall thickness was also observed using nanoindentations on a Hysitron Triboindenter. TM The load was $5 \mathrm{mN}$, and the penetration depth approximately $150 \mathrm{~nm}$.

Figure 9 (a) schematically shows a longitudinal cross-section of a sack where arrays of nanoindentations were placed. Each symbol on Figure 9(a) shows the position of a separate $5 \mathrm{x}$ 5 array. The hardness trend in Figure 8 was also evident in Figure 9(b). Converting $\mathrm{nH}$ data in Fig. 9(b) to $\mathrm{kg} / \mathrm{mm}^{2}$, the hardness is approximately $45 \%$ higher than that in Fig. 8; however, the trend is the same.

In considering these data, note that the method of measuring $\mathrm{HV}$ and $\mathrm{nH}$ differs. The former uses optical measurements of residual impressions and the latter has shallower penetration and uses displacement sensors. Nanoindentation hardness numbers are commonly higher than for microindentation tests on the same material due to differences in methodology, sampling depth, and sensitivity to specimen preparation methods. 


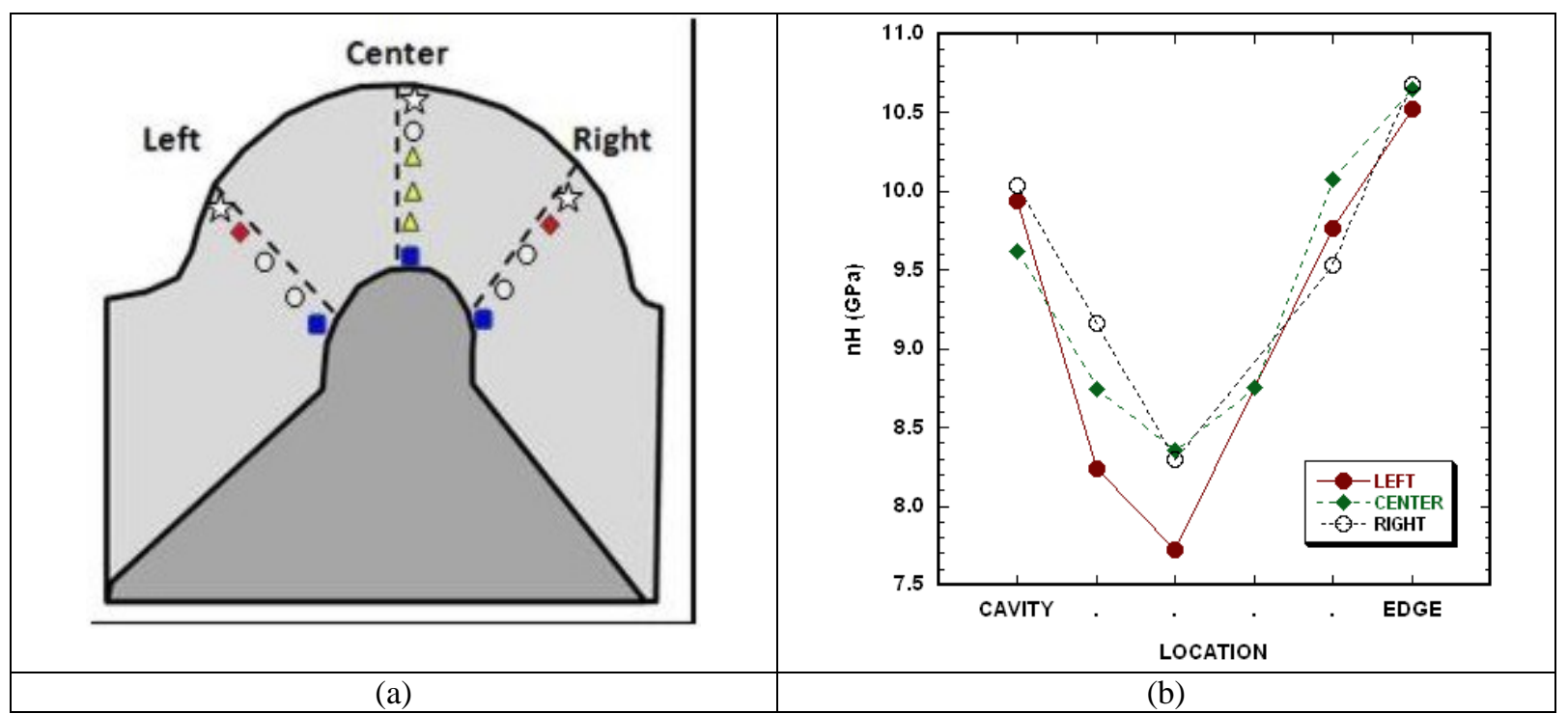

Figure 9. (a) Locations of the three sets of $5 \times 5$ indent arrays used to profile $\mathrm{nH}$. (b) Average nanoindentation hardness $(\mathrm{nH})$ profiles from the nozzle cavity to the outer edge of the sack.

Attempts were also made to measure the nanoindentation hardness of the thin zone of recast material surrounding the spray holes. The area was tested unetched to avoid complications of nanoindenting the rougher, etched surface. Therefore, it was not clear whether the indentations actually fell within a recast zone. They were close enough to the inside bore of the holes, based on measurements of the average zone thickness. Several nanoindentations were placed in these very near surface areas, but except for one or two values of approximately $12 \mathrm{GPa}$, there was no verifiable difference in $\mathrm{nH}$ compared with the material farther away from the holes. There are several possible reasons for this:

- The nanoindentation hardness method and its test-to-test scatter were unable to detect clear differences in near hole-wall hardness compared with that of the bulk.

- The few anomalously higher $\mathrm{nH}$ values of 12 GPa could in fact be real, and thus indicate a harder recast layer.

- Metallographic polishing artifacts swamped subtle differences in $\mathrm{nH}$ in the regions near spray holes.

- The $\mathrm{nH}$ was actually the same in the recast layer as it was in the underlying material, but for different reasons. The recast layer was a rapidly-quenched, fine-grained material, and the underlying material was a heat-treated steel with high hardness.

In summary, there is some evidence that the recast layer is about $20 \%$ harder than the bulk material around the spray holes, but testing difficulties made it difficult to confirm this. 


\subsection{Residual Stress Studies}

Residual stress in a fatigue-critical area of a component part can affect the nucleation and propagation of life-limiting cracks. The shape and size of the fuel injector tips presented significant challenges for residual stress analysis. Several facilities were visited and trial measurements made in an effort to investigate the feasibility of obtaining useful residual stress data on fuel injector nozzle tips. A summary of these studies is given in Table 2.

Table 2. Summary of X-ray and Neutron Techniques Investigated To-Date.

\begin{tabular}{|c|c|c|c|}
\hline Technique & Facility & Sample Examined & Comments/findings \\
\hline Laboratory XRD & ORNL-PTS goniometer & $\begin{array}{l}\text { Prior bending fatigue } \\
\text { test rods }\end{array}$ & $\begin{array}{l}\text { Compressive axial surface stresses } \\
\text { resulting from carburizing heat treatment }\end{array}$ \\
\hline $\begin{array}{l}\text { Synchrotron XRD } \\
\text { (medium energy x-ray) }\end{array}$ & $\mathrm{NSLS}^{*}-\mathrm{X} 14 \mathrm{~A}$ beam line & Injector nozzles & $\begin{array}{l}\text { Compressive stresses at surface } \\
\text { Beam size limited to } 1 \times 2 \mathrm{~mm} \text {. For } 18 \mathrm{Kev} \\
\text { X-rays the depth of measurement is } \\
\text { about } 10 \mu \mathrm{m}\end{array}$ \\
\hline $\begin{array}{l}\text { Synchrotron XRD } \\
\text { (high energy x-ray) }\end{array}$ & APS $^{\star \star}$, ALS $^{\star \star}$ at Stanford & Injector nozzles & $\begin{array}{l}\text { Goals were depth mapping a gauge } \\
\text { volume below } 0.3 \times 0.3 \times 0.3 \mathrm{~mm} \text {. Access } \\
\text { to these facilities was not obtained, } \\
\text { partially due to CRADA work not being } \\
\text { within their scientific-based scope of } \\
\text { work. }\end{array}$ \\
\hline Neutron diffraction & $\mathrm{HFIR}^{\star \star \star \star *}$ - NRSF2 beam line & Injector nozzles & $\begin{array}{l}\text { Measured d-spacing through barrel wall. } \\
\text { Gauge volume limited to } 0.5 \times 0.5 \times 5 \mathrm{~mm} \text {. } \\
\text { Unable to determine stress free } \mathrm{d} \text {-zero } \\
\text { needed to calculate strains. Possible } \\
\text { gauge volume not small enough. }\end{array}$ \\
\hline
\end{tabular}

* National Synchrotron Light Source, ${ }^{* \star}$ Advanced Photon Source, ${ }^{* \star *}$ Advanced Light Source, ${ }^{* \star * *}$ High-Flux Isotope Reactor, National Residual Stress Facility number 2.

The National Synchrotron Light Source (NSLS) at Brookhaven National Lab (Figure 10) was used to measure 3 fuel injector nozzles (with 4 locations on each, parallel x-ray beam). The first sample mounted was heat treated, with no holes. Stresses were measured in the flat area on an injector tip next to the sack in both radial and hoop strain directions. There was also an attempt to examine locations on the tip. In both locations two stress directions were attempted. Results for the hole-less and the specimen with EDM holes consistently showed small stresses. There was very little shift in peak position with tilt. There were plans to try the Advanced Photon Source (APS) at Argonne National Lab (higher-energy) to try to improve the resolution of the materials near the tip (microtomography), but access to the facility, scheduling, and satisfying the user requirements for the facility made such work impractical.

Figure 11 shows data from NSLS beam line X14A showing the rather large error bars on the data and only a faint indication of residual compressive stress. 


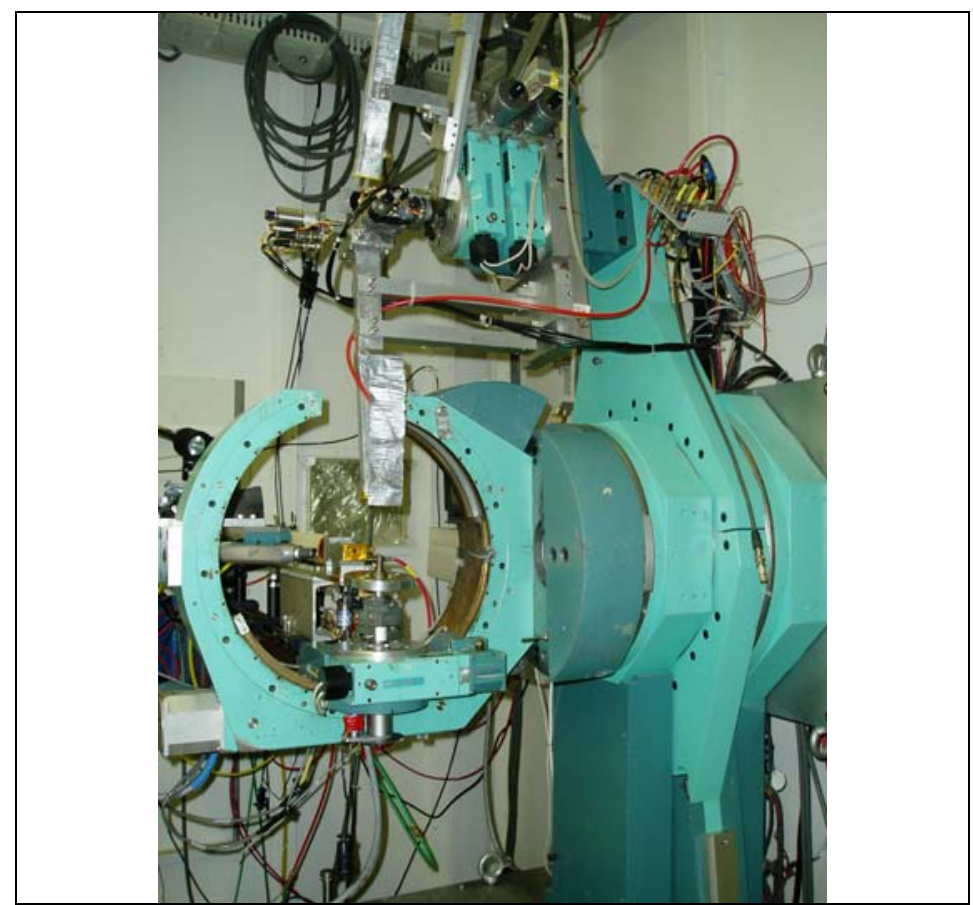

Figure 10. Four circle goniometer at the X14A beam line at NSLS showing the nozzle in place (left of center).

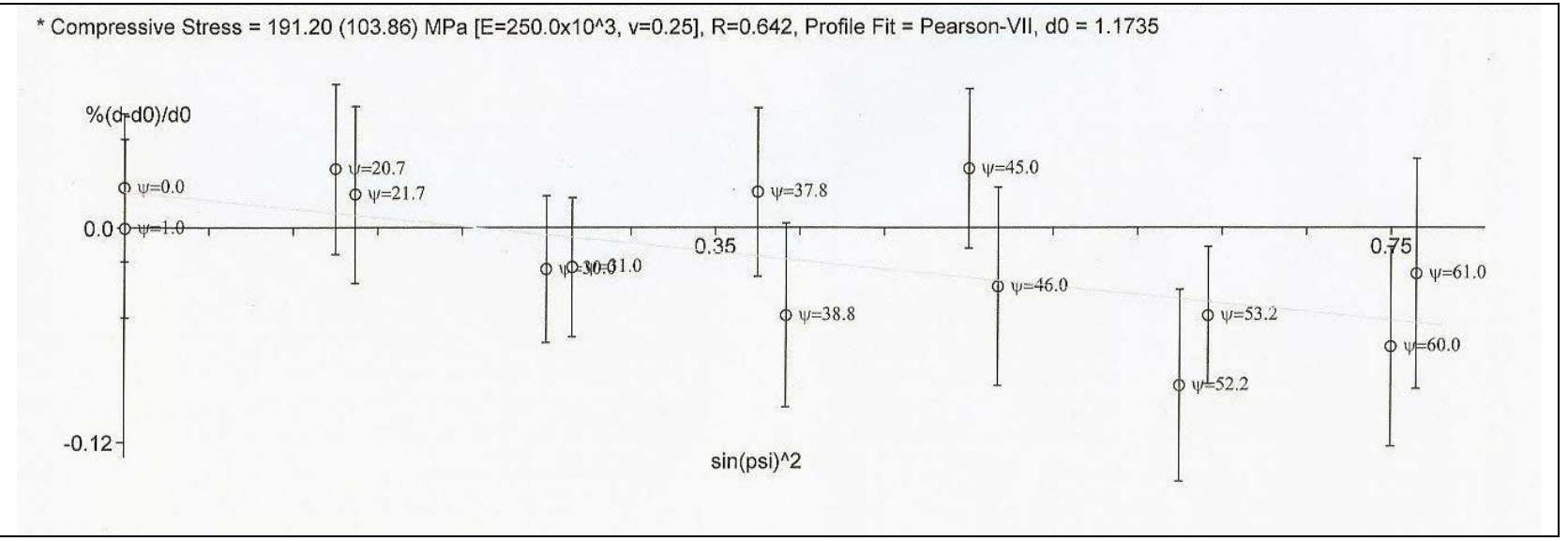

Figure 11. Residual stress data from X14A showing a slight negative tendency (values below 0 indicating compressive stress).

The National Residual Stress Facility (NRSF2) was used to collect diffraction data (d-spacings, intensity, and breadth) for the hoop and radial strain directions in the barrel of a finished nozzle. Later trials used higher spatial resolution solutions compared to earlier methods. These later trials used $0.3 \mathrm{~mm}$ wide slits and up-stream slits to reduce vertical beam divergence by about factor of 5 . The gauge volume cross section was found to be of order of $0.5 \mathrm{~mm}$. A tall thin 
incident slit was used for hoop and axial strains in the barrel region $(0.3 \mathrm{~mm}$ wide $\mathrm{x} 10 \mathrm{~mm}$ high). Longitudinal specimen orientation was not measured because it requires a cubic gauge volume about 30 times smaller than could be used for the radial and hoop directions in the barrel. In the neutron diffraction strain mapping method an accurate strain-free d-spacing is needed to convert d-spacings to strains. The collected data showed large changes in d-spacing between asmachined and heat-treated nozzles, which is consistent with the effects of heat-treatment. Unfortunately, there is clearly a large chemical gradient due to the carburization of the surface, and the change in d-spacings could not be directly related to stresses.

Mapping the sack would require a cubic gauge volume. However, to map with a spatial resolution appropriate for the sack dimensions it would be quite small. At NRSF2, slits as small as $0.3 \mathrm{~mm}$ are available, but the counting time based on barrel measurements would be so long as to be impractical. No neutron diffraction mapping measurements were made in the tip region because of the high gradients in the strain-free d-spacing and the exceptionally long counting times that would be required.

There was insufficient flux for so small a gauge volume, or to characterize the tip (sack) region of the nozzle, a region that lacks the symmetry and vertical height of the barrel. The challenge of analyzing a carburized surface chemical gradient also still remains.

Given the practical limitations on spatial resolution, it was decided not to pursue further neutron stress mapping of the nozzles or sacks.

\subsection{Fatigue Studies}

\subsubsection{Rotating Bending Fatigue}

Rotating bending fatigue (RBF) tests were performed at room temperature for the current alloy as well as several candidate alloys. Normalized test results are shown in Figure 12. The results show that, in the ultra-high cycle fatigue (UHCF) regime, the current alloy along with the current treatment produces the highest fatigue performance among all materials explored. Candidate alloy 1 possesses highest high-cycle and low cycle fatigue strength, but then its fatigue strength falls sharply in the UHCF regime. Candidate alloys 2-5 did not perform as well as the current alloy.

It must be noted that rotating bend fatigue tests were carried out at room temperature. The candidate materials with higher alloy content may still outperform current alloy in UHCF at elevated temperature. Additional RBF tests should be carried out at elevated temperatures near those of the application. That study is suggested for future work. 


\section{S-N}

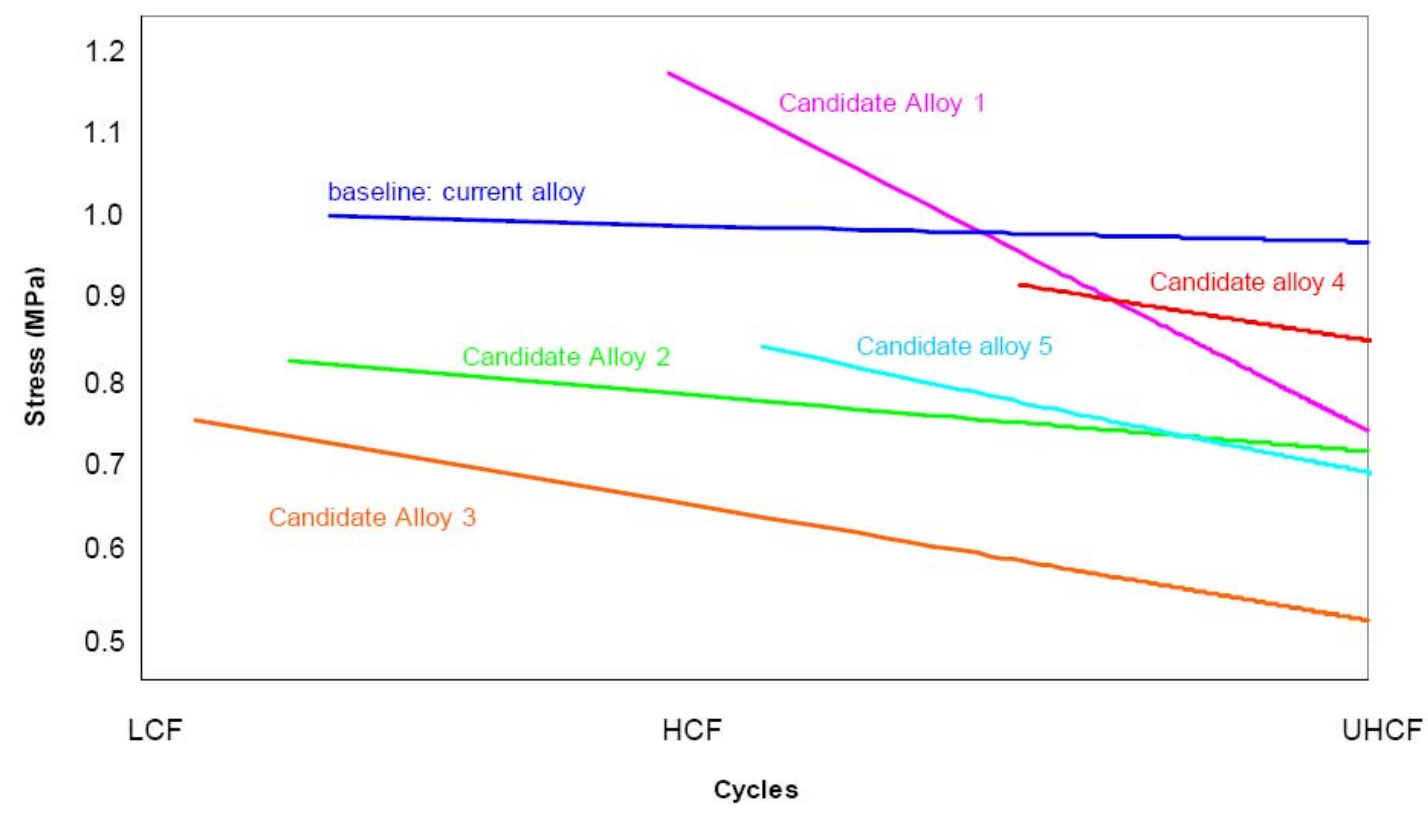

Figure 12. Normalized RBF test results of current and candidate fuel injector materials. (S-N refers to Stress versus Number of Cycles, LCF = low cycle fatigue, HCF = high-cycle fatigue, UHCF = ultra-high cycle fatigue)

A failure analysis and microstructure study was carried out to understand the steep reduction of UHCF strength of candidate alloy 1 . Figure 13 is a SEM image of the fatigue initiation region on the UHCF fracture surface of a RBF specimen from candidate alloy 1 . It shows that the fatigue failure is initiated from an inclusion about $120 \mu \mathrm{m}$ beneath the surface. Further X-ray EDS analysis (company confidential and not shown) revealed that the inclusion is related the surface treatment applied and is therefore intrinsic to candidate alloy 1.

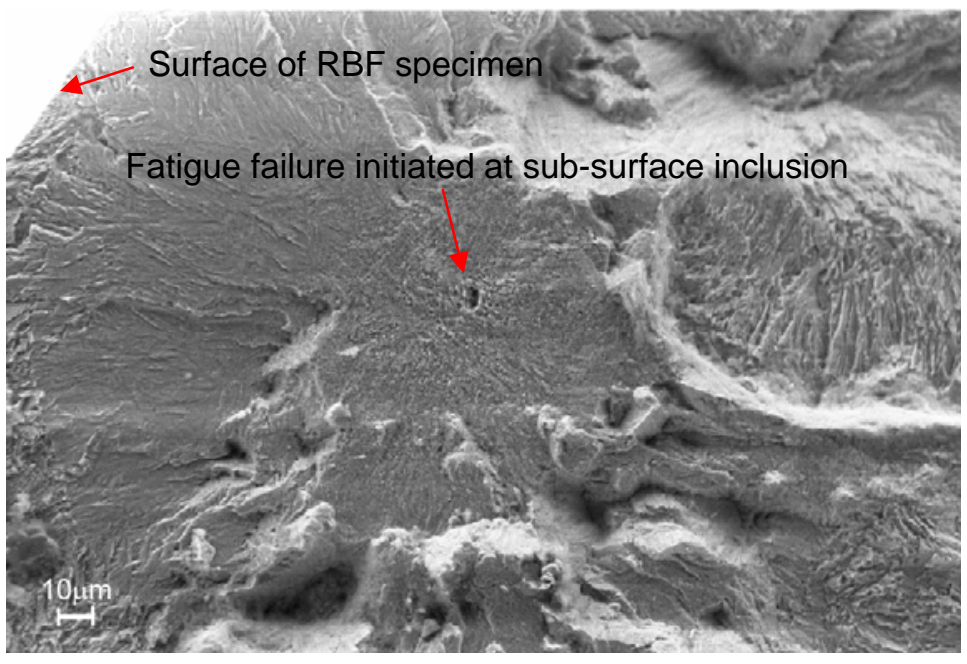

Figure 13. SEM image of an UHCF fracture surface of candidate alloy 1. 


\subsubsection{Smooth Axial Fatigue}

A through-hardness heat treatment was performed on extruded rods of the current alloy steel nozzle material prior to machining the fatigue specimens. Fatigue tests were performed in an MTS 810 uniaxial servohydraulic fatigue testing system under load control at a testing frequency of $20 \mathrm{~Hz}$. All tests were performed at a load-ratio of -1 . The fracture surface of failed specimens was examined by standard stereomicroscopy and field emission gun scanning electron microscopy (SEM) techniques.

The smooth specimen fatigue behavior of the current alloy steel material, at a load ratio of -1 and testing frequency of $20 \mathrm{~Hz}$, is shown in Figure 14. Its fatigue endurance limit was found to be $800 \mathrm{MPa}$. No test specimens with a maximum stress less than $800 \mathrm{MPa}$ failed, but the specimen with $\sigma_{\max }=800 \mathrm{MPa}$ failed in $3.68 \times 10^{7}$ cycles.

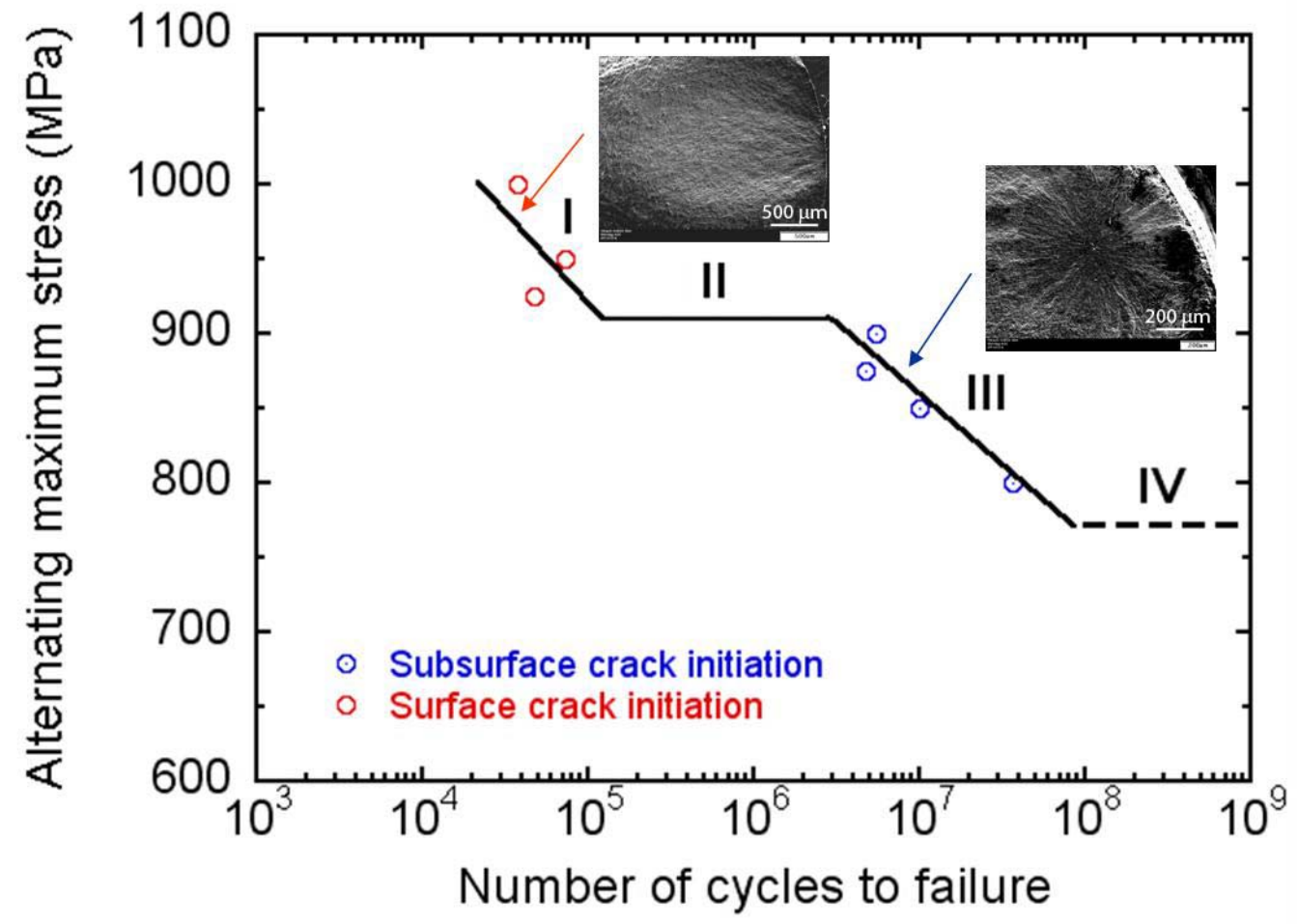

Figure 14: The smooth specimen fatigue behavior of the candidate tool steel material. Clear separation in the crack initiation regions in terms of low-life and long-life failure is observed for these specimens.

Figure 14 indicates that clear separation was observed between the low lifetime failures due to surface crack initiation and long lifetime failures due to sub-surface crack initiation. The separation in the lifetimes based on maximum stress has been observed for several ferrous alloys. Regions I - IV as defined by Mughrabi [2] are included in Fig. 14. Region I corresponded to low lifetime failure from a surface grain or combination of grains. It is likely that crack propagation 
constituted a large portion of the total fatigue lifetime in Region I. Region II corresponds to the persistent slip band (PSB) formation threshold as defined by the conventional endurance limit. Region III included failure from subsurface crack initiation from inclusions with classic "fisheye" type failures observed for this tool steel material. Chemical analysis performed on the inclusions (not shown) indicated that the inclusions were rich in aluminum, oxygen and sulfur. An inclusion could be identified in every long life failure as the origin of the fatigue crack. For maximum stress values lower than region III, a very high cycle fatigue limit corresponding to region IV can be defined.

\subsubsection{Notched Axial Fatigue}

The fatigue crack propagation tests were performed on cylindrical specimens containing opposite-facing, large end-radius $(28 \mathrm{~mm})$ flats on their gauge sections. A notch was wire EDMed at the center of one of the opposite-facing flats. The gage section of a specimen with a machined and polished flat, containing an EDM notch, is shown in Figure 15. The diameter of the notch was of the order of $\sim 300 \mu \mathrm{m}$ and was similar to its depth. The gage section side with the EDM notch was hand polished to a finish of $1 \mu \mathrm{m}$ to aid in the observation and measurement of fatigue cracks. Crack length was measured with a long distance Questar (QM 100) telescope focused on the center of the specimen containing the EDM notch and crack.

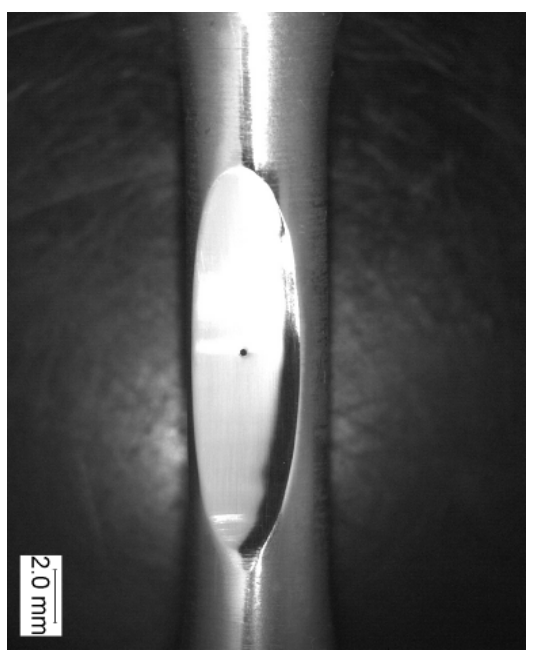

Figure 15. The polished gage section of a specimen with an EDM notch in the center of the gage section. The notch provides a site for forced crack initiation. The loading direction was vertical.

An example of a fatigue crack emanating from a simulated spray hole is shown in an image captured from a Questar ${ }^{\mathrm{TM}}$ telescope in Figure 16. The cracks propagate nominally in the pure mode I plane, and the resultant plasticity occurs around the crack-tip. The fatigue crack propagation behavior of these small cracks at two different maximum stress values are summarized in Figure 17. It can be observed that the crack propagates from the EDM notch at $\sigma_{\max }=700 \mathrm{MPa}$, i.e. below the very high cycle fatigue limit. The Paris law [3] constants according to da/dN $=\mathrm{C}(\Delta \mathrm{K})^{\mathrm{m}}$ are also included in Figure 17. There was no discernible effect of maximum stress on fatigue crack propagation at equivalent values of stress intensity factor range. 


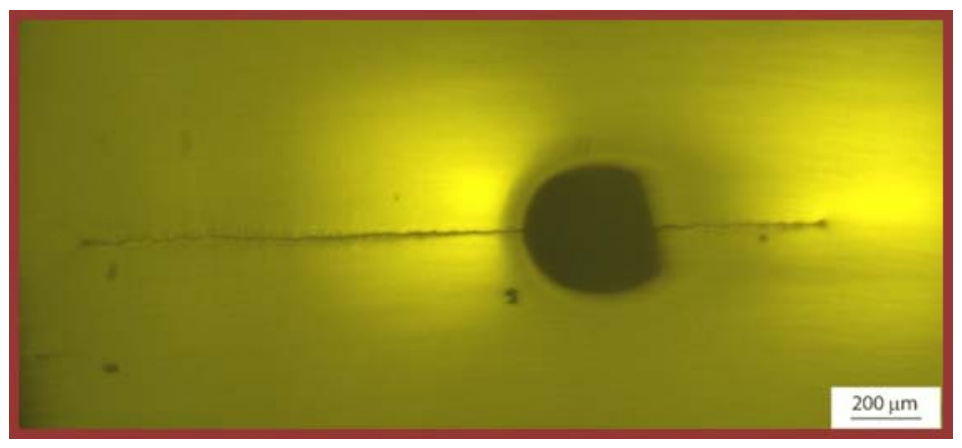

Figure 16. An example image showing the propagation of a small fatigue crack from a simulated spray hole EDMed in the center of the gage section of a fatigue specimen. The loading direction is vertical.

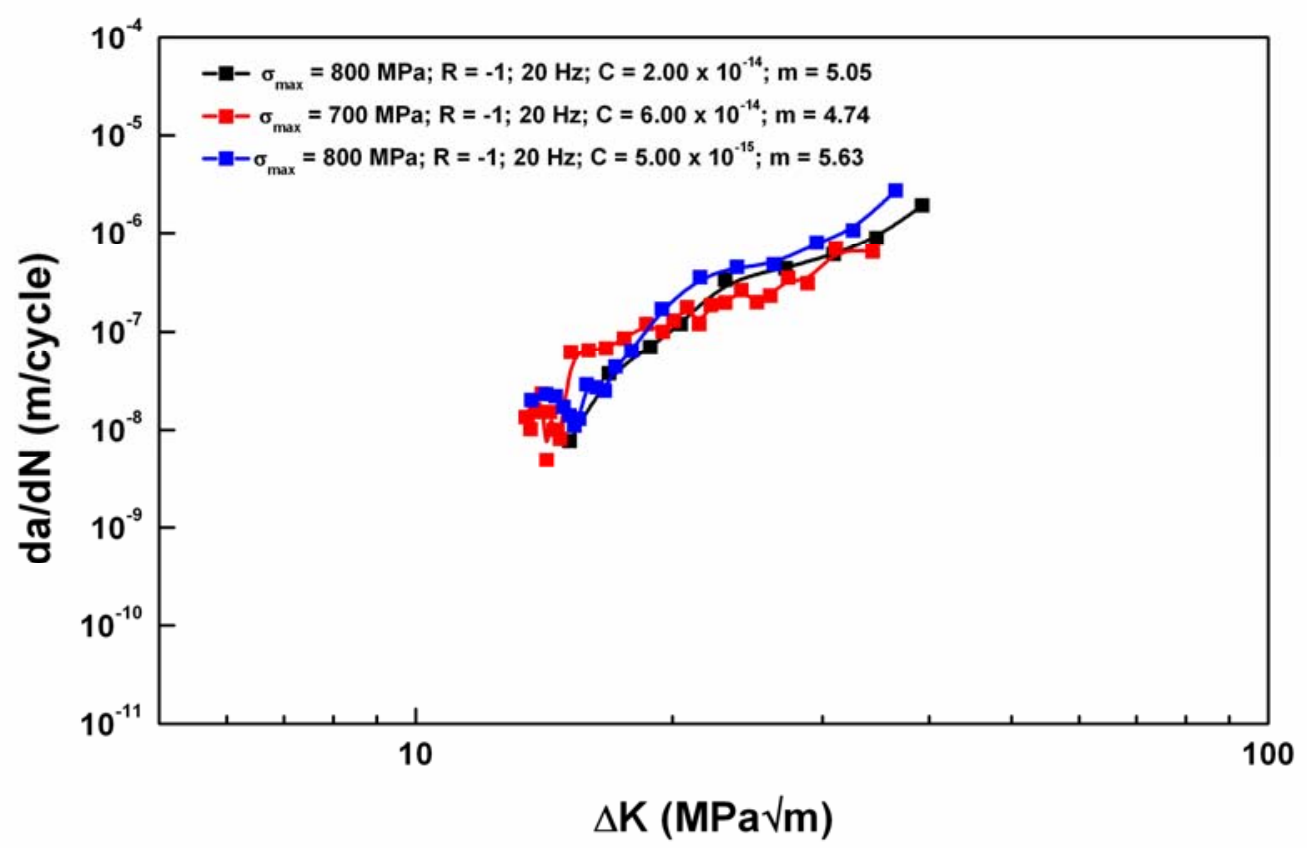

Figure 17. The propagation behavior of cracks emanating from the simulated spray holes. Two different maximum stress levels were evaluated.

The slope of the fatigue crack propagation curves in Figure 17 is similar to that for other high strength materials such as titanium and nickel-base superalloys [4]. Cracks that initiated from simulated EDM spray holes as shown in Figure 16 showed an incubation period that was a significant fraction of the total fatigue life of notched fatigue specimens.

EDM notching led to a severe reduction in the total fatigue life of specimens compared to the smooth specimens. A reduction in fatigue life of nearly four orders of magnitude can result from an EDM notch about the size of the fuel injector spray holes. This result illustrates that evaluating the initiation and propagation behavior of cracks from small spray holes is important when compiling design data for the next generation diesel fuel injection devices. This is 
especially relevant since the current design methodologies rely on smooth specimen fatigue testing results and different materials can have varying levels of notch fatigue resistance.

The smooth specimen and crack propagation behavior of a high strength tool steel material for diesel fuel injection applications is reported. It may be concluded that the fatigue behavior of specimens with simulated spray holes should be determined for design data as opposed to smooth specimen fatigue behavior alone.

\subsection{Subject Inventions and Publications}

\subsection{Inventions}

(none)

\subsection{Publications/Presentations}

P. J. Blau, J. Y. Howe, D. Coffey, R. M. Trejo, L. R. Walker, B. C. Jolly, and N. Wang, "Microstructure, Morphology, and Nanomechanical Properties Near Fine Holes Produced by Electro-Discharge Machining," in preparation for the journal Materials Engineering and Performance (2011).

A. Shyam, P. J. Blau, T. Jordan, N. Yang and M. J. Pollard, “The Very High Cycle Fatigue behavior of Tool Steel Materials" in the Proceedings of the Fifth International Conference on High Cycle Fatigue, Eds. C. Berger and H.-J. Christ, DVM, 2011, pp. 525-530.

A. Shyam, P. Blau, T. Jordon and N. Yang, “The fatigue behavior of alloy steels,” in preparation for ASM Materials Science and Technology Conference and Expo, Columbus, OH (October 16-20, 2011).

\subsection{Commercialization Possibilities}

By working with a diesel engine manufacturer as a partner in this effort, the products of this work are made readily available for commercialization. The majority of the research described here was done on existing fuel injector nozzle materials to determine whether their fatigue characteristics and microstructural attributes would be suitable for advanced, high-pressure fuel injectors, or whether new alloys would be required. To date, there are no direct indications that the current material would not perform well if manufactured to high standards; however, there was no data available or provided to ORNL on the current materials when tested in advanced high-pressure injection systems, so the current results cannot be directly compared with the performance of the current materials in that more demanding environment. 


\subsection{Plans for Future Collaboration}

The current report contains information on the smooth and notched-fatigue properties and microstructures of alloy steel materials used in current fuel injector nozzles which contain fine fuel-spray holes. These data will serve as a benchmark for evaluating the performance of advanced metal alloys for similar applications. Future collaboration will depend on whether the current material can effectively resist the high injection pressures in evolving diesel engine designs as they come into the market. Additional issues concerning residual stress characterization around nozzle sacks still remain, and these may be explored in future collaborative efforts.

\subsection{Conclusions}

An investigation was conducted of the microstructures, spray hole geometry, residual stresses, and smooth and notched fatigue performance of Caterpillar's current fuel injector nozzles and the steel alloy from which they are fabricated. The following conclusions were drawn:

1) Spray hole walls in injector spray tips produced by EDM are rough on a micro-scale, and provide numerous possible sites for crack nucleation. Fine-scale details of the hole walls, revealed by scanning and transmission electron microscopy confirm this. However, there is no field evidence from used injectors to suggest that fatigue cracks do nucleate at hole walls under pulsed pressure loading. Yet, when emerging systems are run at ultra-high injection pressures, the smoothing of EDM hole walls could decrease the chance for cracks to nucleate there. This is a subject for further study as future field experience with ultra-high pressure injectors builds.

2) Neither neutron diffraction nor x-ray based residual stress mapping methods indicated more than a mild level of compressive stress in fuel injector nozzle walls. The small sample volumes in the sack area, and their dome-like shape, prevented high-resolution measurement of localized residual stress gradients in the areas surrounding the holes. As residual stress methods improve, this issue should be revisited.

3) Rotating beam fatigue tests of current and candidate alternative materials showed encouraging results for the current alloy, compared to candidate alloys being studied by the CRADA partner; however, these results used smooth specimens without spray holesized features in the fatigue cracking location.

4) Smooth specimen axial fatigue behavior of current fuel injector steel materials displayed a dual mode crack initiation behavior. At stresses higher than about $800 \mathrm{MPa}$, cracks started at machining flaws in the surface, but at lower stresses, the cracks initiated in the bulk microstructure below the surface. This suggests that for the next generation for high-pressure fuel injector nozzles, it becomes increasingly important to control the 
machining and finishing processes, especially if the stresses imposed on the nozzle walls approach or exceed that threshold level.

5) Fatigue tests were conducted using spray hole-sized EDM notches in the gage sections of the same shaped specimens that were used for axial fatigue tests. Compared to the smooth specimens, notching led to a reduction in total fatigue life of nearly four orders of magnitude. Consequently, the initiation and propagation behavior of cracks from small spray holes is relevant for the next generation diesel fuel injectors. This concern is especially relevant since the current design methodologies tend to rely on smooth specimen fatigue testing results, and different materials can have varying levels of notch fatigue resistance.

\subsection{References}

1. R. Morgan, J. Wray, D. A. Kennaird, C. Crua, and M. R. Heikal (2001) “The Influence of Injector Parameters on the Formation and Break-Up of a Diesel Spray,” SAE Technical Paper 2001-01-0529, 12 pp.

2. H. Mughrabi (1999) "On the life-controlling fatigue mechanisms in ductile metals and alloys in the gigacycle regime," Fatigue and Fracture of Engineering Materials and Structures, Vol. 22 (7), pp. 633-641.

3. P.C. Paris, M.P. Gomez, and W.E. Anderson (1961) “A rational analytic theory of fatigue,” The Trend in Engineering, Vol. 13, pp. 9-14.

4. A. Shyam, D. E. Allison, C. J. Szczepanski, T. M. Pollock, and J. W. Jones (2007) "Small crack growth in metallic materials: A model and its application to engineering alloys," Acta Materialia, Vol. 55, pp. 6606-6616.

\subsection{Symbols and Nomenclature}

\subsection{Symbols}

a length of a growing crack measured from the mid-point of the flaw that initiated it; for the growth of a crack extending laterally on both sides of a starting flaw, like a spray hole or an indentation, the total crack length (including both sides) would be 2a

$\mathrm{C}$ a geometric constant that is used to compute the crack growth rate for a given stress intensity level

$\mathrm{da} / \mathrm{dn}$ the instantaneous increase in the crack length of a growing fatigue crack per imposed stress cycle

$\mathrm{Hz} \quad$ oscillating frequency in stress cycles per second (Hertz)

$\mathrm{m} \quad$ an exponent used to fit fatigue crack growth rate data to imposed stress (Paris law)

MPa unit of pressure or stress, megapascals, equivalent to 1,000,000 newtons per square meter

$\mathrm{R} \quad$ ratio of the maximum to the minimum stress imposed per cycle during a fatigue test 
$\mathrm{Ra} \quad$ arithmetic average surface roughness (micrometers or microinches) of a surface along a given sampling length

$\mathrm{Rz} \quad$ the difference between the average heights of the top five peaks and lowest five valleys of a surface roughness profile ('ten-point height'), usually expressed in micrometers or microinches

$\Delta \mathrm{K} \quad$ the range in stress intensity imposed per fatigue cycle on the tip of a growing crack due to the imposed force and crack tip geometry

$\sigma_{\max } \quad$ maximum level of alternating stress applied during a fatigue test

\subsection{Nomenclature}

CRADA Cooperative Research And Development Agreement, a legal means by which federal research facilities can work collaboratively with industry and ensure a measure of intellectual property protection for shared data and hardware designs.

EDM Electro-discharge machining, a controlled sparking process commonly used to create fine spray holes in a fuel injector sack

EDS Energy Dispersive Spectroscopy, sometimes called EDX, it is a method of surface chemical analysis obtained by descretizing and counting the x-ray photon energies produced at localized regions of a surface under a collimated electron beam, as in an SEM or TEM with the proper attachments

FIBS focused ion beam thinning system used to prepare electron-transparent TEM specimens

HFIR High Flux Isotope Reactor at ORNL

HV Vickers micro-indentation hardness number, expressed in units of pressure (kg$\mathrm{f} / \mathrm{mm}^{2}$ ) obtained from a four-faceted diamond indenter with a $136^{\circ}$ edge-to-edge angle, applied to a surface under specified load and withdrawn to enable optical measurement of the impression diagonal lengths.

$\mathrm{nH}$ nano indentation hardness number, expressed in units of pressure (GPa), obtained from precise measurements of the depth of penetration of a trigonal diamond indenter under applied loads in the milli-newton range

NRSF2 National Residual Stress Facility number 2 at the HFIR

NSLS National Synchrotron Light Source, a national x-ray facility at Brookhaven National Laboratory

ORNL Oak Ridge National Laboratory

RBF rotating bending fatigue, a test involving the rotation of a cylindrical, hour-glassshaped test specimen in a fixture with a load applied at one end, causing the periphery of the necked central portion of the specimen to experience alternating tensile and compressive stresses, and usually leading to a fatigue fracture that signals the end of the test

sack The dome-shaped tip of a cylindrical fuel injector nozzle

SEM Scanning Electron Microscope

TEM Transmission Electron Microscope 